\title{
Thermal and Thermo-Mechanical Properties of Poly(L-lactic Acid) Biocomposites Containing $\beta$-Cyclodextrin/D-Limonene Inclusion Complex
}

\author{
Monika Dobrzyńska-Mizera ${ }^{1, *}$, Monika Knitter ${ }^{1} \oplus$, Salvatore Mallardo ${ }^{2}$, Maria Cristina Del Barone ${ }^{2}$, \\ Gabriella Santagata ${ }^{2}$ and Maria Laura Di Lorenzo ${ }^{2}$ (i) \\ 1 Institute of Materials Technology, Polymer Division, Poznan University of Technology, Piotrowo 3, \\ 61-138 Poznan, Poland; monika.knitter@put.poznan.pl \\ 2 National Research Council (CNR), Institute of Polymers, Composites and Biomaterials (IPCB), \\ c/o Comprensorio Olivetti, via Campi Flegrei, 34, 80078 Pozzuoli, NA, Italy; \\ salvatore.mallardo@ipcb.cnr.it (S.M.); cristina.delbarone@ipcb.cnr.it (M.C.D.B.); \\ gabriella.santagata@ipcb.cnr.it (G.S.); marialaura.dilorenzo@ipcb.cnr.it (M.L.D.L.) \\ * Correspondence: monika.dobrzynska-mizera@put.ponan.pl
}

Citation: Dobrzyńska-Mizera, M.; Knitter, M.; Mallardo, S.; Del Barone, M.C.; Santagata, G.; Di Lorenzo, M.L. Thermal and Thermo-Mechanical Properties of Poly(L-lactic Acid) Biocomposites Containing $\beta$-Cyclodextrin/D-Limonene Inclusion Complex. Materials 2021, 14 2569. https://doi.org/10.3390/ ma14102569

Academic Editor: Christoforos Krontiras

Received: 1 April 2021

Accepted: 12 May 2021

Published: 15 May 2021

Publisher's Note: MDPI stays neutral with regard to jurisdictional claims in published maps and institutional affiliations.

Copyright: (c) 2021 by the authors. Licensee MDPI, Basel, Switzerland. This article is an open access article distributed under the terms and conditions of the Creative Commons Attribution (CC BY) license (https:// creativecommons.org/licenses/by/ $4.0 /)$.

\begin{abstract}
Bio-based composites made of poly(L-lactic acid) (PLLA) and $\beta$-cyclodextrin/D-limonene inclusion complex (CD-Lim) were prepared by melt extrusion. Encapsulation of volatile D-limonene molecules within $\beta$-cyclodextrin cages was proven to be a successful strategy to prevent evaporation during high-temperature processing. However, small amounts of limonene were released upon processing, resulting in the plasticization of the polymeric matrix. Morphological analysis revealed good dispersion of the filler, which acted as a nucleating agent, favoring the growth of PLLA crystals. The composites' lowered glass transition temperature upon the addition of CD-Lim was also proved by thermomechanical analysis (DMA). Moreover, DMA revealed constant stiffness of modified materials at room temperature, which is crucial in PLLA-based formulations.
\end{abstract}

Keywords: biocomposites; thermomechanical properties; thermal analyses; extrusion

\section{Introduction}

Poly(L-lactic acid) (PLLA) is a thermoplastic aliphatic polyester produced from annually renewable resources, which is biodegradable, compostable, and biocompatible [1]. Among the various biodegradable and bio-based polymers, PLLA has the highest potential to replace traditional petroleum-based polymeric materials. PLLA is currently used in multiple industrial fields, including biomedicine, packaging, automotive, and electronic industries [2], with considerable growth expected in applications where a relatively short lifetime can be forecasted, such as food packaging [3].

Significant research efforts have been devoted to promoting PLLA and other biodegradable polymers for active food packaging [4]. This type of packaging incorporates components that can release or absorb substances into or from the packaged goods or that can grant a tailored headspace composition within the package [5]. Introducing active ingredients towards specific pathogens in the package's formulation also reduces the need for synthetic food additives and has a positive health impact [6]. Among the various additives currently used as food preservatives and active ingredients in food packaging, essential oils (EOs) play a prominent role as antifungal and antiviral agents [7-11]. EOs are natural volatile substances produced by plants and are hence excellent candidates to be added to a packaging that aims to not only be active but also bio-based, like a PLLA-based packaging [12].

However, incorporation of essential oils into PLLA is not a straightforward procedure. The boiling point of most essential oils is well below the melt processing temperature of PLLA, which prevents direct melt mixing of the components and hinders further processing 
of the material aimed at obtaining films by casting, compression molding, or extrusion. Moreover, most EOs are miscible with PLLA and plasticize the polymer, with marked and sometimes unwanted side effects on material properties, such as migration from the polymer matrix [13-16]. A possible route to overcome these problems is to incorporate essential oils within cyclodextrins, cage-like cyclic oligosaccharides produced from starch, a renewable natural material [17]. Cyclodextrin (CD) molecules can form inclusion complexes with various non-polar, aliphatic, and aromatic compounds. They are able to incorporate antimicrobials agents and, as a result, control their release, influence the product's quality, and prolong its suitability for consumption [18]. The capability to embody fine particles within their hollows led to the considerable usage of cyclodextrins in a vast application area, such as pharmaceutical, food, and cosmetic industries. The inclusion of a volatile guest particle strongly decreases its diffusivity and volatility, hence protecting it from oxidation and thermal decomposition $[19,20]$. Thus, the bioactive compounds included inside the hydrophobic CDs cage can be feasibly carried and released by polymer matrices.

In a previous manuscript, we reported that D-limonene (4-isopropenyl-1methylcyclohexane), the antimicrobial component of citrus peels, can be successfully encapsulated within $\beta$-CD [21], the CD modification made of seven glucopyranose units [17]. The incorporation inside $\beta$-CD enhanced D-limonene's (Lim) thermal stability allows its melt processing with poly(butylene succinate) (PBS) [21].

D-limonene is a natural antimicrobial agent [22-24] itemized in the Code of Federal Regulations and commonly identified as a harmless flavoring agent and food preservative [25]. Its antibacterial activity has been proven with various types of food-related microorganisms, such as Staphylococcus aureus, Listeria monocytogenes, Salmonella enterica, Saccharomyces bayanus, etc. [26,27].

Based on the successful inclusion of the CD-Lim complex within PBS, which allowed development of fully biobased and biodegradable composites, we prepared novel composites based on PLLA as polymer matrix and CD-Lim as a dispersed phase. Inclusion of CD-Lim within PLLA by melt-processing, instead of PBS, is challenging since PLLA has a much higher melting temperature than PBS $\left(160-200^{\circ} \mathrm{C}\right.$ vs. $\left.115^{\circ} \mathrm{C}\right)$, which may result in sizable evaporation of volatile Lim (boiling point $176^{\circ} \mathrm{C}$ ) upon melt processing. Therefore, considerable care was taken to prepare the composites, including proper choice of the PLLA grade and tailored processing conditions. The selected PLLA grade, detailed below, has $4 \%$ of D-isomer units, which implies a lower melting temperature than more stereoregular grades [1], hence, it can be melt-processed at lower temperatures. Details on the preparation and chemico-physical properties of PLLA/CD-Lim composites are reported in this manuscript, where it is shown that the proposed strategy allows incorporation of D-limonene within PLLA. The results presented here serve as basis to test suitability of the prepared materials for food packaging, with data detailed in a forthcoming manuscript [28] where mechanical, barrier, optical, and antibacterial/antifungal properties of PLLA/CD-Lim films are presented and discussed.

\section{Materials and Methods}

A poly(L-lactic acid), LX175, abbreviated PLLA, with MFR $6 \mathrm{~g} / 10 \mathrm{~min}\left(210{ }^{\circ} \mathrm{C}\right.$, $2.16 \mathrm{~kg}$ ), and containing $4 \%$ of D-isomer units in the chain, was kindly provided by Corbion (The Netherlands). $\beta$-cyclodextrin (CD) with a purity $\geq 99 \%$, provided by Cyclodextrin Shop, was used after drying. A technical D-limonene grade ( $\approx 90 \%$ purity), abbreviated Lim, was supplied by Sigma Aldrich.

An inclusion complex of $\beta$-cyclodextrin and D-limonene was obtained via precipitation method [21]. First, $420 \mathrm{~g}$ of cyclodextrin was dissolved in $4200 \mathrm{~mL}$ of solution of ethanol and water $(1: 2)$ at $55^{\circ} \mathrm{C}$. D-limonene dissolved in ethanol $(10 \% v / v)$ was gently poured to the heated CD solution under constant stirring, which was then held for an additional $4 \mathrm{~h}$ at room temperature. Then, the mixture was kept at $4{ }^{\circ} \mathrm{C}$ for $24 \mathrm{~h}$. The filtrated CD-Lim complex was dried at $50{ }^{\circ} \mathrm{C}(24 \mathrm{~h})$ and further at $25^{\circ} \mathrm{C}(24 \mathrm{~h})$. As reported in [21], this procedure leads to $7 \mathrm{wt} \%$ of $\mathrm{D}$-limonene in $\beta$-cyclodextrin. 
All materials were dried under vacuum at $50{ }^{\circ} \mathrm{C}$ for $24 \mathrm{~h}$ before processing. PLLA pellets were mixed with CD-Lim complex in a Retsch GM 200 rotary mixer (Haan, Germany) for $3 \mathrm{~min}$ at $2000 \mathrm{rpm}$. Based on results detailed in [21], composites containing a sizable amount of D-limonene, sufficient to ensure antimicrobial properties [28] were prepared. Mixing of the materials with various CD-Lim amounts (0-30 wt\%) was carried out with a Zamak corotating twin-screw extruder (Skawina, Poland) operated at $190^{\circ} \mathrm{C}$ and $60 \mathrm{rpm}$. The extruded rod was pelletized upon cooling in air. Compositions were selected to have a sizable amount of Lim in the composites, with PLLA/CD-Lim composites containing 20 and $30 \mathrm{wt} \%$ of CD-Lim, as summarized in Table 1.

Table 1. Symbols and mass concentrations of samples.

\begin{tabular}{lccc}
\hline \multirow{2}{*}{ Designation } & \multicolumn{3}{c}{ Mass Concentration (wt\%) } \\
\cline { 2 - 4 } & PLLA & CD-Lim & Lim \\
\hline PLLA & 100 & 0 & 0 \\
PLLA/20CD-lim & 80 & 20 & 1.2 \\
PLLA/30CD-lim & 70 & 30 & 1.6 \\
\hline
\end{tabular}

The composites were compression-molded with a Collin Laboratory Forming Press $\mathrm{P}$ $200 \mathrm{E}$ (Chengdu, China) at a temperature of $190^{\circ} \mathrm{C}$ for $3 \mathrm{~min}$, without any pressure applied to allow complete melting. After this period, a load of about 200 bar was applied for $3 \mathrm{~min}$, then the samples with a thickness of $1 \mathrm{~mm}$ were air-cooled to room temperature. A similar procedure was followed to produce thin films with a thickness of approx. $150 \mu \mathrm{m}$. In this case, compression molding was conducted at $175^{\circ} \mathrm{C}$ without any pressure, followed by an application of a load of about 10 bar for $1 \mathrm{~min}$, and further 200 bar for another $1 \mathrm{~min}$. Finally, the samples were air-cooled to room temperature.

Thermal properties were investigated with a Netzsch DSC 204 F1 Phoenix ${ }^{\circledR}$ (Selb, Germany) apparatus, using aluminum crucibles and approximately $3 \pm 0.5 \mathrm{mg}$ samples under nitrogen flow. High purity standards were used to calibrate the instrument, including indium, tin, bismuth, zinc, and aluminum. The indium melting enthalpy was used for energy calibration. All the samples were heated to $200^{\circ} \mathrm{C}$ and held in a molten state for $5 \mathrm{~min}$, followed by cooling to $-60^{\circ} \mathrm{C}$ at heating and cooling rates of $10^{\circ} \mathrm{C} \mathrm{min}^{-1}$.

TGA analyses were performed in the temperature range between 30 and $600{ }^{\circ} \mathrm{C}$, at a heating rate of $10^{\circ} \mathrm{C} \mathrm{min}-1$, under a nitrogen atmosphere using a Netzsch TG 209 F1 apparatus (Selb, Germany) calibrated by analyzing several standards, including In, Sn, Bi, $\mathrm{Zn}, \mathrm{Al}$, and $\mathrm{Ag}$. The decomposition onset temperature, $T_{\mathrm{o}}$, of approximately $10 \mathrm{mg}$ samples, was determined at the intersection of tangents to two branches of the thermogravimetric curve [29]. Each measurement was preceded by an empty pan run, and subtracted from each thermogram to correct instrumental drift.

Dynamic mechanical analysis was carried out using an Anton Paar model Physica MCR 301 rheometer (Graz, Austria) in torsion mode. With dimensions of $10 \times 4 \times 50 \mathrm{~mm}$, the composites underwent analysis in a temperature range between 25 and $130{ }^{\circ} \mathrm{C}$ at a frequency of $1 \mathrm{~Hz}$ and a heating rate of $2{ }^{\circ} \mathrm{C} \mathrm{min}^{-1}$.

Cryogenically fractured cross-sections of PLLA-based composites were analyzed using a Quanta 200 FEG, 338 FEI scanning electron microscope (Thermo Fisher Scientific, Eindhoven, The Netherlands). SEM microphotographs were collected at room temperature and a voltage of $20 \mathrm{kV}$. Before analysis, surfaces of the samples were sputter-coated with an $18 \pm 0.2 \mathrm{~nm}$ layer of Au-Pd alloy by a MED 020 splattering device, Bal-Tec AG (Pfaffikon, Switzerland).

\section{Results and Discussion}

Our previous investigation demonstrated that D-limonene can be successfully included within $\beta$-cyclodextrin via precipitation, with proof of inclusion provided by infrared spectroscopy, ${ }^{13} \mathrm{C}$ Nuclear Magnetic Resonance X-ray diffraction, and thermogravimetry [21]. Being the same procedure, only TGA analysis is repeated here as a tool to verify 
the efficacy of new sample preparation, as TGA can also provide quantitative analysis of the effective amount of Lim encapsulated within $\beta$-CD. TGA plots of pure $\beta$-cyclodextrin, $\mathrm{D}$-limonene, as well as $\beta$-cyclodextrin/D-limonene inclusion complex are presented in Figure 1.

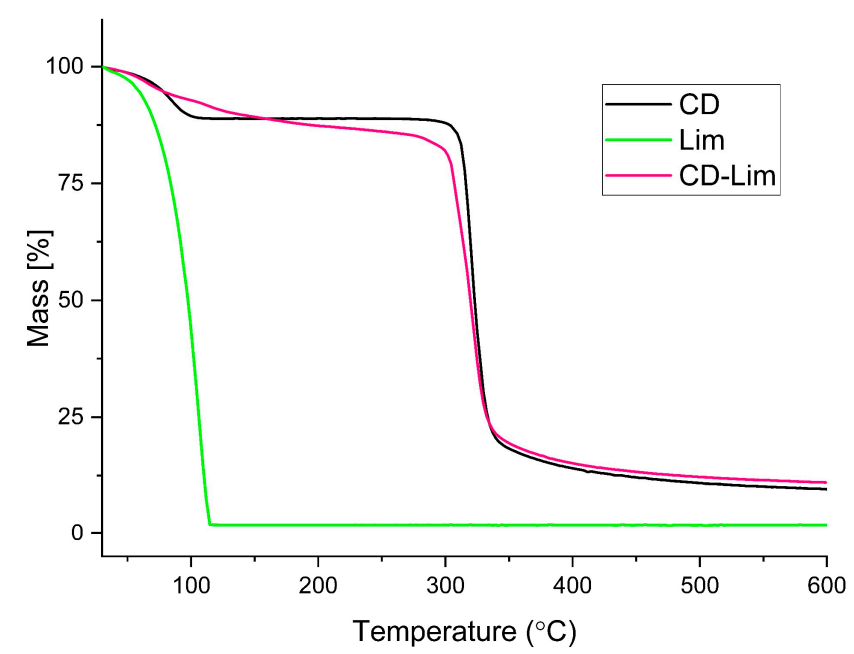

Figure 1. Thermogravimetric plots of $\beta$-cyclodextrin (black curve), D-limonene (green curve), and $\beta$-cyclodextrin/D-limonene inclusion complex (magenta curve), upon heating at $10{ }^{\circ} \mathrm{C} \mathrm{min}^{-1}$ in nitrogen.

TGA curve of neat $\beta$-CD displays three significant mass loss steps. The first one, of $12 \%$ of the initial mass, was caused by the release of free and freeze-bound water up to about $110^{\circ} \mathrm{C}$. The second one starts around $300^{\circ} \mathrm{C}$ and was related to a rapid mass loss of about $70 \%$, due to depolymerization of cyclodextrin macromolecules and glucosidic rings, with the creation of carbonyl group and carbon-carbon double bonds [30]. The final thermal degradation stage occurred above $340{ }^{\circ} \mathrm{C}$ and revealed a slow thermal degradation of the residual char. In case of the CD-Lim, two degradation steps occurred in the range of $25-300{ }^{\circ} \mathrm{C}$. The first one, ranging between $50-105{ }^{\circ} \mathrm{C}$, reached a mass loss of about $8 \%$ due to the release of water and possibly also of a minor amount of Lim. Around $105^{\circ} \mathrm{C}$, a second, smaller mass decrease starts and finishes slightly below $300{ }^{\circ} \mathrm{C}$, where the initial mass was cut to an overall 15\% (7\% in the second stage). This second step was caused by loss of the terpene, whose thermal stability is largely enhanced by encapsulation within $\beta-C D$ cavity [30-32]. Moreover, TGA data of Figure 1 permits quantification of the amount of essential oil encapsulated within $\beta-C D$, which is about $7 \% w / w$, in agreement with Ref. [21].

The TGA curves of PLLA and PLLA/CD-Lim sheets measured upon heating at $10{ }^{\circ} \mathrm{C} \mathrm{min}^{-1}$ and normalized to the initial sample mass are presented in Figure 2a, with the first derivative curves shown as in Figure 2b. Plain PLLA exhibits a one-stage degradation process, where the polymer decomposes completely at about $380^{\circ} \mathrm{C}$, due to chain-end scission resulting in a constant lowering of molar mass [33-36]. Addition of CD-Lim complex to PLLA largely varies the mass-temperature profile, leading to a two-step degradation process due to different temperature ranges of degradation of the matrix and the filler. The lower thermal stability of CD-Lim, compared to plain PLLA, seen by comparison of the plots shown in Figures 1 and 2, results in an enhanced onset of mass loss in the composites. The derivative plot of the composite containing $30 \%$ of the filler displays a small peak centered around 150-160 C, barely visible also for the sample containing 20\% of CD-Lim, which possibly reveals evaporation of water, in agreement with Figure 1 (the samples were not dried before TGA analysis). This overlaps with Lim's gradual release from $C D$ upon heating of PLLA, completed upon depolymerization of $\beta-C D$, with the exact temperature being affected by composition. Possible interactions between the polar 
groups of $\beta$-CD surface and carbonyl groups of PLLA induce a joint impact on thermal decomposition kinetics, resulting in varied thermal stability of the composites depending on filler content. The delayed thermal degradation of CD-Lim in the sample containing a higher filler amount, revealed by the peak around $300{ }^{\circ} \mathrm{C}$ in the first derivative plots shown in Figure $2 b$, reveals a protective effect of the matrix against thermal degradation of the filler. Conversely, CD-Lim seems not to affect the thermal stability of PLLA, which occurs at temperatures where the filler is mostly decomposed.

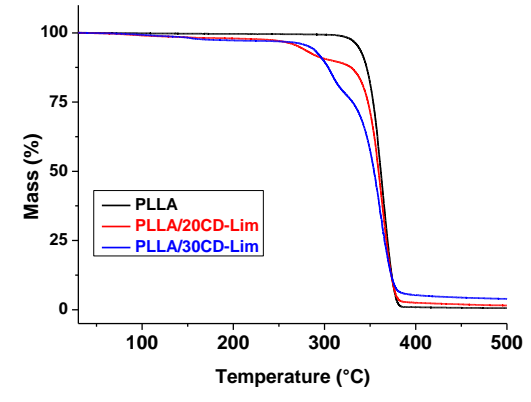

(a)

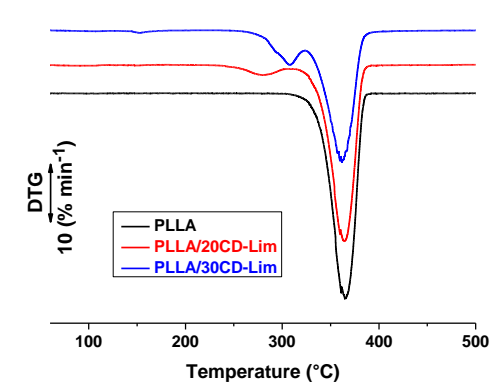

(b)

Figure 2. Thermogravimetric analysis of PLLA and PLLA/CD-Lim composites upon heating at $10^{\circ} \mathrm{C}$ min $^{-1}$ in nitrogen atmosphere: mass loss as a function of temperature (a) and the first derivative of the mass loss vs. temperature curves $(\mathbf{b})$.

Morphology of PLLA/CD-Lim composites was investigated by scanning electron microscopy. The electron micrographs of fractured cross-sections of pure PLLA, PLLA/20CDLim, and PLLA/30CD-Lim composites are compared in Figure 3 at the same magnification. Figure 3a shows the fractured surfaces of compression molded, neat PLLA, which is smooth, as expected. The addition of $20 \mathrm{wt} \%$ of CD-Lim (Figure $3 \mathrm{~b}$ ) results in varied morphology, with the appearance of small voids and embedded particles homogeneously distributed along the whole surface of the sample. With the increase of filler content (30 $\mathrm{wt} \%$, Figure $3 \mathrm{c}$ ), the electron micrograph shows several discrete microdomains distributed inside the polymeric matrix; some of them are agglomerated in small clusters. Agglomeration may be favored by the cyclodextrin hydrophilic surfaces and higher concentration inside the polymer matrix. It is worth noting that only a part of the filler particles were pulled out during the cryogenic fracture process; some of the particles remained attached to the matrix, suggesting compatibility between the components.

Thermal analysis of PLLA and PLLA/CD-Lim composites are presented in Figure 4 as heat flow rate plots in a temperature function. Figure 4a reports the thermograms detailing the first heating scan of the compression molded sheets, whereas Figure $4 \mathrm{~b}$ displays the second heating scan of the same samples after cooling at a constant rate of $10^{\circ} \mathrm{C} \mathrm{min}-1$. The DSC thermogram of compression molded, plain PLLA displays a glass transition $\left(T_{\mathrm{g}}\right)$ at $66^{\circ} \mathrm{C}$ coupled with enthalpy relaxation, followed by a cold crystallization exotherm and a double melting peak. The latter is often observed in thermal analysis of PLLA and is linked to melting of two crystal modifications, named $\alpha^{\prime}$ and $\alpha[1,37,38]$. Glass transition of the composites, centered at $62{ }^{\circ} \mathrm{C}$ for both analyzed compositions, slightly shifted to lower temperatures, due to partial release of D-limonene from $\beta$-CD cages to the PLLA matrix upon melt processing. The amount of Lim dissolved in PLLA was very similar in the two compositions (1.2-1.6 $\mathrm{wt} \%$, as quantified below) and results in a minor difference in plasticization, and practically overlapping $T_{\mathrm{g}} \mathrm{s}$ of the composites. It needs to be underlined that the measured $T_{\mathrm{g}}$ of the composites, which is $4{ }^{\circ} \mathrm{C}$ lower than in PLLA, well compares to literature data of PLLA/Lim formulations, as addition of much larger amounts (20 wt\%) of Lim was reported to lead to a decrease of $T_{\mathrm{g}}$ of about $30^{\circ} \mathrm{C}$ with respect to PLLA [39]. 

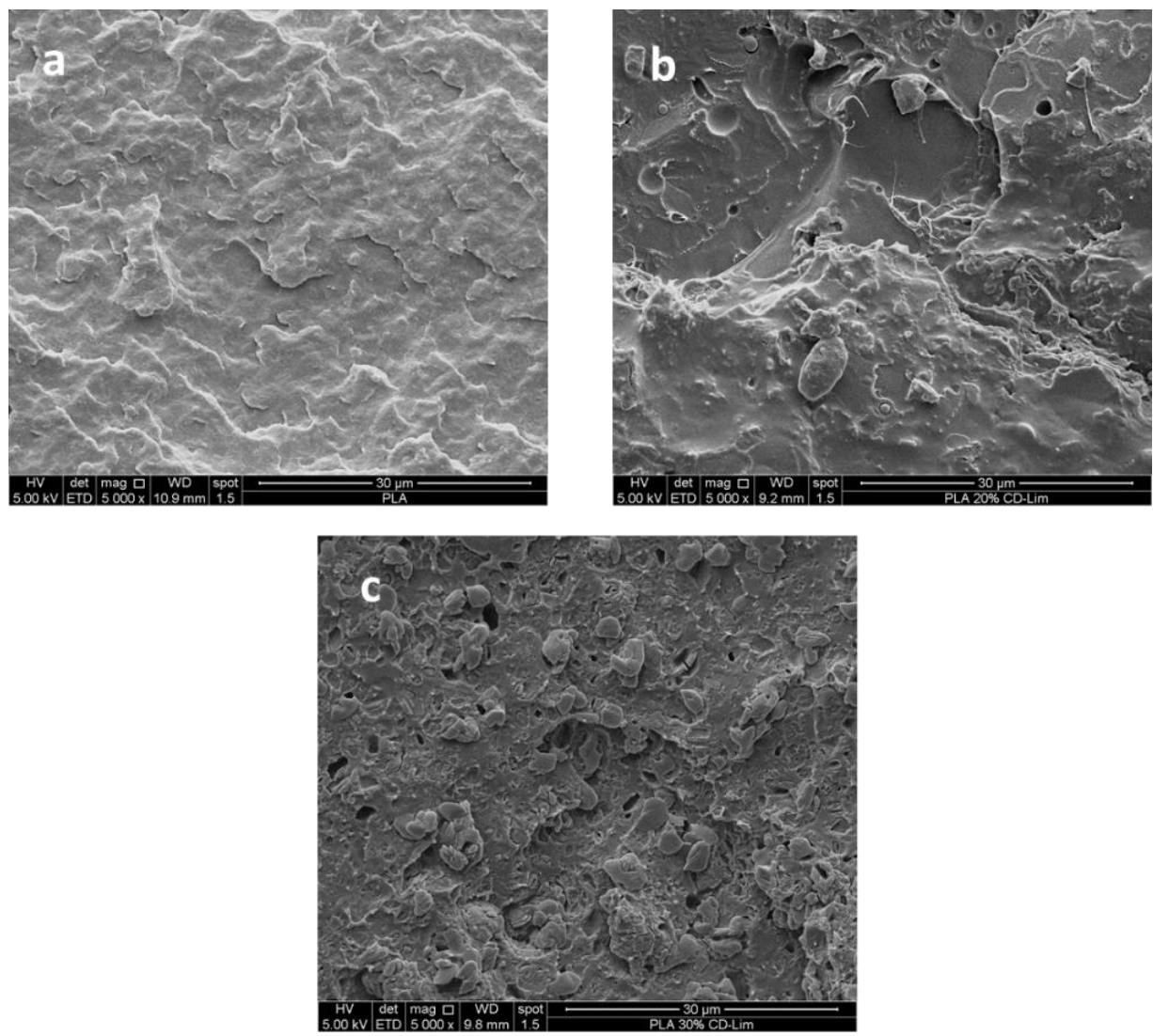

Figure 3. SEM micrographs of PLLA (a), PLLA/20CD-Lim (b), and PLLA/30CD-Lim (c) cryogenically fractured surfaces.

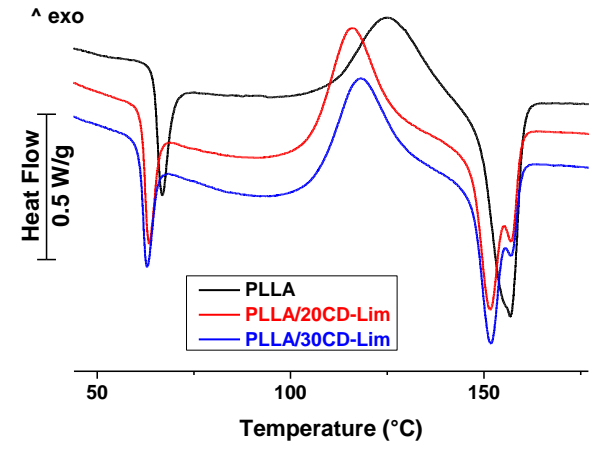

(a)

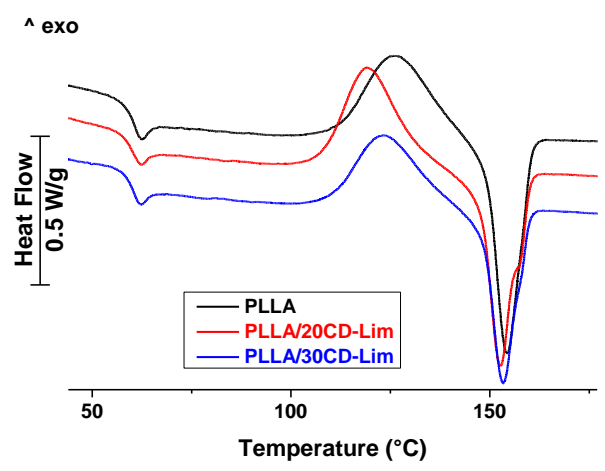

(b)

Figure 4. Heat flow rate plots of PLLA and PLLA/CD-Lim composites upon heating at $10^{\circ} \mathrm{C} \min ^{-1}$ : (a) heating scan of the compression-molded sheets and (b) heating scan of the same samples after cooling at $10{ }^{\circ} \mathrm{C} \mathrm{min}^{-1}$. Exotherm upward.

Above $T_{\mathrm{g}}$, the composites display a broad endotherm extending from the end of $T_{\mathrm{g}}$ to the onset of cold crystallization. This is caused by evaporation of a small fraction of Lim, which was released from the $\beta-C D$ cages upon melt processing, and remained dissolved within the PLLA matrix, slightly plasticizing it. The enhanced molecular mobility above $T_{\mathrm{g}}$ allows release of the volatile component, resulting in a broad endotherm in the DSC plot.

The cold crystallization exotherm evidences an anticipated onset in the composites, compared to plain PLLA. This is linked to the varied crystallization window caused by plasticization, which shifts the phase transition to lower temperatures [40]. The initial slope of the cold crystallization peak increases with CD-Lim content, i.e., crystallization proceeds 
faster in the initial stage of the phase transition, as typically occurs in the presence of nucleating agents [41]. The multiple melting of PLLA, due to melting of $\alpha^{\prime}$ - and $\alpha$-crystals was only slightly varied in the composites, being determined by the cold crystallization temperature and crystal reorganization occurring upon heating [38].

Analysis of the weak endotherms between $T_{\mathrm{g}}$ and the onset of cold crystallization allows quantification of the amount of Lim that evaporates upon heating. Integration of these endothermic peaks leads to an enthalpy of 3.6 and $4.3 \mathrm{~J} \mathrm{~g}^{-1}$ for the samples containing 20 and $30 \mathrm{wt} \%$ of CD-Lim, respectively. Considering that enthalpy of vaporization of Dlimonene is equal to $284 \mathrm{~J} \mathrm{~g}^{-1}$ [42], about 1.2 and $1.6 \mathrm{wt} \%$ of Lim evaporated upon DSC heating of the composites with 20 and $30 \mathrm{wt} \%$ of CD-Lim, respectively. This is the amount of D-limonene released from the $\beta$-CD cages upon melt processing, which remained dissolved within PLLA amorphous chain portions, plasticizing the polymer matrix.

Cooling at $10{ }^{\circ} \mathrm{C} \mathrm{min}{ }^{-1}$ did not allow crystallization of the polymer, as expected for a PLLA grade containing $4 \%$ D-isomer units $[37,38,43]$, and results in the subsequent heating, in a marked cold crystallization exotherm, followed by a melting endotherm of similar size, as seen in Figure 3b. Unlike the first heating, in the second heating scan, $T_{\mathrm{g}}$ seems to slightly increase with filler content, but with a minor variation that falls within experimental uncertainty. No endotherm of evaporation of Lim can be evidenced in the temperature range between $T_{\mathrm{g}}$ and the onset of cold crystallization, proving that all limonene that was initially dissolved within PLLA had already evaporated upon previous heating. This rationalizes the invariance of $T_{\mathrm{g}}$ with the composition seen in Figure $4 \mathrm{~b}$. It needs to be underlined that, similarly to the data shown in Figure $4 \mathrm{a}$, cold crystallization of PLLA starts at lower temperatures in the composites compared to the plain polymer, confirming that CD-Lim can promote the onset of crystallization of PLLA.

Thermo-mechanical properties of PLLA/CD-Lim composites were also investigated. Figure 5 shows the storage modulus $\left(E^{\prime}\right)$ and damping factor ( $\tan \delta$ ) of PLLA/CD-Lim composites. At low temperatures, all samples display a storage modulus of about $2 \times 10^{9} \mathrm{~Pa}$, as typical of glassy polymer, with slight variations among the grades close to the experimental uncertainty. By raising the temperature, glass transition occurs around $60^{\circ} \mathrm{C}$, as revealed by the sudden drop of $E^{\prime}$ and the sharp peak detected in $\tan \delta$ plots. In the composites, $T_{\mathrm{g}}$ takes place at slightly lower temperatures than plain PLLA [44,45], in agreement with DSC data of Figure 4a. Upon further increase of the temperature, at about $90^{\circ} \mathrm{C}$, PLLA chains gain sufficient mobility to cold crystallize, which results in a sizable rise in $E^{\prime}$. Consequently, the segmental motion and molecular relaxation processes drastically reduced, as evidenced by the decreasing of $\tan \delta$ both intensity and amplitude [46].

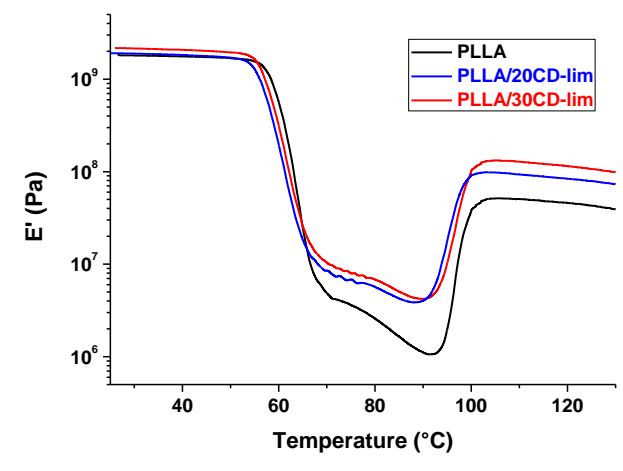

(a)

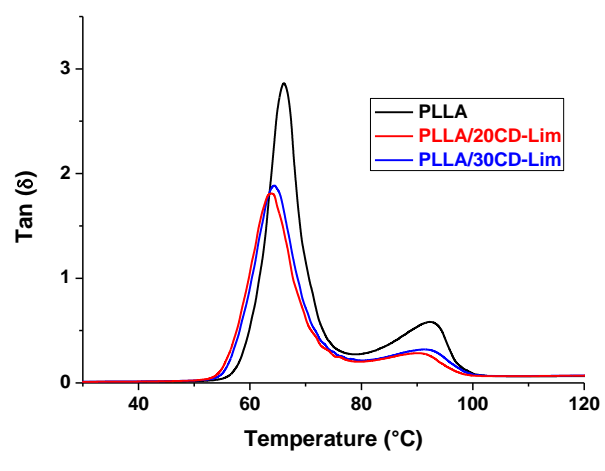

(b)

Figure 5. Storage modulus $\left(\mathrm{E}^{\prime}\right)(\mathbf{a})$ and damping factor $(\tan \delta)(\mathbf{b})$ vs. temperature of PLLA and PLLA/CD-Lim composites at heating rate of $2{ }^{\circ} \mathrm{C} \min ^{-1}$ and frequency of $1 \mathrm{~Hz}$.

Cold crystallization has an anticipated onset in the composites compared to the plain polymer, which corroborates the knowledge gained by DSC analysis. The onset of crystallization was measured at about $90^{\circ} \mathrm{C}$ by DMA upon heating at $2{ }^{\circ} \mathrm{C} \min ^{-1}$ (Figure 5a) 
and at about $100{ }^{\circ} \mathrm{C}$ by DSC upon heating at $10{ }^{\circ} \mathrm{C} \mathrm{min}^{-1}$ (Figure 4a). The lower heating rate in DMA allows more time for chain ordering, favoring crystal nucleation and growth at lower temperatures, which results in an anticipated onset of cold crystallization [47]. After completion of crystallization, the storage modulus appeared to be sizably affected by the filler's presence, as it increases with CD-Lim content. This effect is not seen at low temperatures below $T_{\mathrm{g}}$, where only minor differences in $E^{\prime}$ values could be measured. At low temperatures, the plasticizing effect of limonene on PLLA matrix counterbalances the raised stiffness due to the presence of the filler. Upon heating, the small amount of D-limonene dissolved in PLLA evaporates, and only the reinforcing effect of the filler remains, causing sizable variation in the storage modulus with composition.

\section{Conclusions}

Composites prepared with PLLA and $\beta$-cyclodextrin containing D-limonene, all biobased, were produced via twin-screw extrusion in different compositions. Encapsulation of $\mathrm{D}$-limonene within $\beta$-cyclodextrin cavities greatly enhances the thermal stability of the essential oil to a level that allows its melt processing with PLLA, without marked loss of the essential oil. The results detailed above demonstrate that this is a successful strategy to incorporate D-limonene within PLLA via melt processing.

The composite films are slightly plasticized by small amounts (about $1.5 \mathrm{wt} \%$ ) of $D$-limonene released from the $\beta-C D$ cages upon melt processing. CD-Lim filler affects crystallization kinetics of PLLA, acting as an efficient nucleating agent, able to promote PLLA crystals growth. All formulations have comparable stiffness at room temperature, which varies with filler content at temperatures above $T_{\mathrm{g}}$. Morphological analysis of the cryogenically fractured samples display a homogeneous distribution of the filler within PLLA, with limited agglomeration observed only at high filler content. Moreover, the filler particles seem to have a good level of adhesion to the PLLA matrix.

The changes in thermal and thermo-mechanical properties and structure, detailed herein, largely influence tensile behavior as well as barrier and optical properties of the PLLA/CD-Lim composites, with results detailed in a submitted manuscript [28]. More importantly, it was proved that the obtained composites have antimicrobial properties, since when PLLA/CD-Lim films are put in contact with a wide range of bacteria and fungi, they can inhibit growth of these microorganisms. Therefore, the PLLA/CD-Lim composites appear to be promising materials for design of active food packaging films [28].

Author Contributions: Conceptualization, M.D.-M., M.K., G.S. and M.L.D.L.; methodology, M.D.M., M.K., G.S. and M.L.D.L.; validation, M.D.-M., M.K., G.S., M.C.D.B. and M.L.D.L.; investigation, M.D.-M., M.K., S.M., M.C.D.B., G.S. and M.L.D.L.; resources, M.D.-M. and M.K.; data curation, G.S. and M.L.D.L.; writing —original draft preparation, G.S. and M.L.D.L.; writing-review and editing, M.D.-M., G.S. and M.L.D.L.; supervision, G.S. and M.L.D.L.; project administration, M.D.-M.; funding acquisition, M.D.-M., M.K. and M.L.D.L. All authors have read and agreed to the published version of the manuscript.

Funding: This research was funded by the National Science Centre in Poland under the Preludium project, grant number UMO-2016/23/N/ST8/03799 and Poznan University of Technology, grant number 0613/SBAD/4710.

Institutional Review Board Statement: Not applicable.

Informed Consent Statement: Not applicable.

Acknowledgments: The authors are grateful to Corbion for supplying PLLA for the research.

Conflicts of Interest: The authors declare no conflict of interest. 


\section{References}

1. Di Lorenzo, M.L.; Androsch, R. Synthesis, Structure and Properties of Poly(Lactic Acid); Advances in Polymer Science; Springer: Berlin, Germany, 2018; Volume 279.

2. Di Lorenzo, M.L.; Androsch, R. Industrial Applications of Poly(Lactic Acid); Advances in Polymer Science; Springer: Berlin, Germany, 2018; Volume 282.

3. Malinconico, M.; Vink, E.T.H.; Cain, A. Applications of Poly(lactic acid) in Commodities and Specialties. In Industrial Applications of Poly(Lactic Acid); Advances in Polymer Science; Springer: Berlin, Germany, 2018; Volume 282.

4. Zhong, Y.; Godwin, P.; Jin, Y.; Xiao, H. Biodegradable polymers and green-based antimicrobial packaging materials: A mini-review. Adv. Ind. Eng. Polym. Res. 2020, 3, 27-35. [CrossRef]

5. European Food Safety Authority (EFSA). Guidelines on submission of a dossier for safety evaluation by the EFSA of active or intelligent substances present in active and intelligent materials and articles intended to come into contact with food. EFSA $J$. 2009, 7, 1208.

6. Moeini, A.; Reenen, A.; Otterlo, W.; Cimmino, A.; Masi, M.; Lavermicocca, P.; Valerio, F.; Immirzi, B.; Santagata, G.; Malinconico, M.; et al. $\alpha$-costic acid, a plant sesquiterpenoid from Dittrichiaviscosa, as modifier of Poly(lactic acid) properties: A novel exploitation of the autochthone biomass metabolite for a wholly biodegradable system. Ind. Crops. Prod. 2020, 146, 112134. [CrossRef]

7. Burt, S. Essential oils: Their antibacterial properties and potential applications in foods-A review. Int. J. Food. Microbiol. 2004, 94, 223-253. [CrossRef] [PubMed]

8. Khaneghah, A.M.; Hashemi, S.M.B.; Limbo, S. Antimicrobial agents and packaging systems in antimicrobial active food packaging: An overview of approaches and interactions. Food Bioprod. Process. 2018, 111, 1-19. [CrossRef]

9. Tariq, S.; Wani, S.; Rasool, W.; Shafi, K.; Bhat, M.A.; Prabhakar, A.; Shalla, A.H.; Rather, M.A. A comprehensive review of the antibacterial, antifungal and antiviral potential of essential oils and their chemical constituents against drug-resistant microbial pathogens. Microb. Pathog. 2019, 134, 103580. [CrossRef]

10. Huang, T.; Qian, Y.; Wei, J.; Zhou, C. Polymeric Antimicrobial Food Packaging and Its Applications. Polymers 2019, 11, 560. [CrossRef] [PubMed]

11. Falleh, H.; Jemaa, M.B.; Saada, M.; Ksouri, R. Essential oils: A promising eco-friendly food preservative. Food Chem. 2020, 330, 127268. [CrossRef]

12. Arrieta, M.P.; López, J.; Ferrándiz, S.; Peltzer, M.A. Characterization of PLA-limonene blends for food packaging applications. Polym. Test. 2013, 32, 760-768. [CrossRef]

13. Sawalha, H.; Schroën, K.; Boom, R. Addition of oils to polylactide casting solutions as a tool to tune film morphology and mechanical properties. Polym. Eng. Sci. 2010, 50, 513-519. [CrossRef]

14. Turco, R.; Tesser, R.; Cucciolito, M.E.; Fagnano, M.; Ottaiano, L.; Mallardo, S.; Malinconico, M.; Santagata, G.; Di Serio, M. Cynaracardunculus Biomass Recovery: An Eco-Sustainable, Nonedible Resource of Vegetable Oil for the Production of Poly(lactic acid) Bioplasticizers. ACS Sustain. Chem. Eng. 2019, 7, 4069-4077. [CrossRef]

15. Arrieta, M.P.; López, J.; Hernández, A.; Rayón, E. Ternary PLA-PHB-limonene blends intended for biodegradable food packaging applications. Eur. Polym. J. 2014, 50, 255-270. [CrossRef]

16. De Oliveira Mori, C.L.S.; Dos Passos, N.A.; Oliveira, J.E.; Altoé, T.F.; Mori, F.A.; Mattoso, L.H.C.; Scolforo, J.R.; Tonoli, G.H.D. Nanostructured polylactic acid/candeia essential oil mats obtained by electrospinning. J. Nanomater. 2015, 2015, 439253.

17. Szejtli, J. Introduction and general overview of cyclodextrin chemistry. Chem. Rev. 1998, 98, 1743-1753. [CrossRef] [PubMed]

18. López-de-Dicastillo, C.; Gallur Ramón Catalá, M.; Gavara, R.; Hernandez-Muñoz, P. Immobilization of $\beta$-cyclodextrin in ethylene-vinyl alcohol copolymer for active food packaging applications. J. Memb. Sci. 2010, 353, 184-191. [CrossRef]

19. Ciobanu, A.; Landy, D.; Fourmentin, S. Complexation efficiency of cyclodextrins for volatile flavor compounds. Food Res. Int. 2013, 53, 110-114. [CrossRef]

20. Kfoury, M.; Landy, D.; Auezova, L.; Greige-Gerges, H.; Fourmentin, S. Effect of cyclodextrin complexation on phenylpropanoids solubility and antioxidant activity. J. Org. Chem. 2014, 10, 2322-2331. [CrossRef] [PubMed]

21. Mallardo, S.; De Vito, V.; Malinconico, M.; Volpe, M.G.; Santagata, G.; Di Lorenzo, M.L. Poly(butylene succinate)-based composites containing $\beta$-cyclodextrin/D-limonene inclusion complex. Eur. Polym. J. 2016, 79, 82-96. [CrossRef]

22. Aggarwal, K.K.; Khanuja, S.P.S.; Ahmad, A.; Santha Kumar, T.R.; Gupta, V.K.; Kumar, S. Antimicrobial activity profiles of the two enantiomers of limonene and carvone isolated from the oils of Menthaspicata and Anethumsowa. Flavour Fragr. J. 2002, $17,59-63$. [CrossRef]

23. Rancic, A.; Sokovic, M.; Griensven, L.J.L.D.; Vukojevic, J.; Brkic, D.; Ristic, M. Antimicrobial activity of limonene. Matieres Med. 2003, 23, 83-88.

24. Zhang, Z.; Vriesekoop, F.; Yuan, Q.; Liang, H. Effects of nisin on the antimicrobial activity of d-limonene and its nanoemulsion. Food Chem. 2014, 150, 307-312. [CrossRef] [PubMed]

25. Sun, J. D-limonene: Safety and clinical applications. Altern. Med. Rev. 2007, 12, 259-264.

26. Chikhoune, A.; Hazzit, M.; Kerbouche, L.; Baaliouamer, A.; Aissat, K. Tetraclinisarticulata (Vahl) Masters essential oils: Chemical composition and biological activities. J. Essent. Oil. Res. 2013, 25, 300-307. [CrossRef]

27. Settanni, L.; Palazzolo, E.; Guarrasi, V.; Aleo, A.; Mammina, C.; Moschetti, G.; Germanà, M.A. Inhibition of foodborne pathogen bacteria by essential oils extracted from citrus fruits cultivated in Sicily. Food Control. 2012, 26, 326-330. [CrossRef] 
28. Dobrzyńska-Mizera, M.; Knitter, M.; Szymanowska, D.; Mallardo, S.; Santagata, G.; Di Lorenzo, M.L. Bio-based composites of poly(L-lactic acid) and D-limonene/ $\beta$-cyclodextrin inclusion complex for active food packaging: Optical, mechanical, and antimicrobial properties. Food Packag. Shelf Life 2021. submitted.

29. Dobrzyńska-Mizera, M.; Knitter, M.; Woźniak-Braszak, A.; Baranowski, M.; Sterzyński, T.; Di Lorenzo, M.L. Poly(L-lactic acid)/pine wood bio-based composites. Materials 2020, 13, 3776. [CrossRef]

30. Trotta, F.; Zanetti, M.; Camino, G. Thermal degradation of cyclodextrins. Polym. Degrad. Stab. 2000, 69, 373-379. [CrossRef]

31. Serafini, M.R.; Menezes, P.P.; Costa, L.P.; Lima, C.M.; Quintans, L.J., Jr.; Cardoso, J.C.; Matos, J.R.; Soares-Sobrinho, J.L.; Grangeiro, S., Jr.; Nunes, P.S.; et al. Interaction of p-cymene with $\beta$-cyclodextrin. J. Therm. Anal. Calorim. 2012, 109, 951-955. [CrossRef]

32. Capelezzo, A.P.; Cassol Mohr, L.; Dalcanton, F.; Muneron de Mello, J.M.; Fiori, M.A. $\beta$-Cyclodextrins as Encapsulating Agents of Essential Oils. In Cyclodextrin-A Versatile Ingredient; Chapter 7; IntechOpen: London, UK, 2018.

33. Zeng, C.; Zhang, N.W.; Feng, S.Q.; Ren, J. Thermal stability of copolymer derived from l-lactic acid and poly(tetramethylene) glycol through direct polycondensation. J. Therm. Anal. Calorim. 2013, 111, 633-646. [CrossRef]

34. Di Lorenzo, M.L.; Ovyn, R.; Malinconico, M.; Rubino, P.; Grohens, Y. Peculiar crystallization kinetics of biodegradable poly(lactic acid)/poly(propylene carbonate) blends. Polym. Eng. Sci. 2015, 55, 2698-2705. [CrossRef]

35. Di Lorenzo, M.L.; Longo, A. N,N-Diethyl-3-methylbenzamide (DEET): A mosquito repellent as functional plasticizer for poly(Llactic acid). Thermochim. Acta 2019, 677, 180-185. [CrossRef]

36. Södergård, A.; Näsman, J.H. Melt stability study of various types of poly(L-lactide). Ind. Eng. Chem. Res. 1996, 35, 732-735. [CrossRef]

37. Androsch, R.; Schick, C.; Di Lorenzo, M.L. Kinetics of Nucleation and Growth of Crystals of Poly(L-lactic acid). In Synthesis, Structure and Properties of Poly(Lactic Acid); Advances in Polymer Science; Springer: Berlin, Germany, 2018; Volume 279, pp. 235-272.

38. Di Lorenzo, M.L.; Androsch, R. Influence of $\alpha^{\prime}$-/ $\alpha$-crystal polymorphism on properties of poly(L-lactic acid). Polym. Int. 2018, 68, 320-334. [CrossRef]

39. Brüster, B.; Adjoua, Y.-O.; Dieden, R.; Grysan, P.; Federico, C.E.; Berthé, V.; Addiego, F. Plasticization of Polylactide with Myrcene and Limonene as Bio-Based Plasticizers: Conventional vs. Reactive Extrusion. Polymers 2019, 11, 1363. [CrossRef] [PubMed]

40. Saeidlou, S.; Huneault, M.A.; Li, H.; Park, C.B. Poly(lactic acid) crystallization. Progr. Polym. Sci. 2012, 37, 1657-1677. [CrossRef]

41. Di Lorenzo, M.L.; Wunderlich, B. Temperature-Modulated Calorimetry of the Crystallization of Polymers Analyzed by Measurements and Model Calculations. J. Therm. Anal. Calor. 1999, 57, 459-472. [CrossRef]

42. Hazra, A.; Dollimore, D.; Alexander, K. Thermal analysis of the evaporation of compounds used in aromatherapy using thermogravimetry. Thermochim. Acta 2002, 392-393, 221-229. [CrossRef]

43. Di Lorenzo, M.L.; Rubino, P.; Luijkx, R.; Hélou, M. Influence of chain structure on crystal polymorphism of poly(lactic acid). Part 1: Effect of optical purity of the monomer. Coll. Polym. Sci. 2014, 292, 399-409. [CrossRef]

44. Ali, F.; Chang, Y.W.; Kang, S.C.; Yoon, J.Y. Thermal, mechanical and rheological properties of poly(lactic acid)/epoxidized soybean oil blends. Polym. Bull. 2009, 62, 91-98. [CrossRef]

45. Ljungberg, N.; Colombini, D.; Wesslen, B. Plasticization of poly(lactic acid) with oligomeric malonate esteramides: Dynamic mechanical and thermal film properties. J. Appl. Polym. Sci. 2005, 96, 992-1002. [CrossRef]

46. Wunderlich, B. Thermal Analysis of Polymeric Materials; Springer: Berlin/Heidelberg, Germany, 2005.

47. Di Lorenzo, M.L.; Silvestre, C. Non-isothermal crystallization of polymers. Progr. Polym. Sci. 1999, 24, 917-950. [CrossRef] 